\title{
Economic aspects of day care after operations for hernia or varicose veins
}

\author{
R. J. PRESCOTT, CONSTANCE CUTHBERTSON, NORMA FENWICK, \\ W. M. GARRAWAY, AND C. V. RUCKLEY \\ From the Medical Computing and Statistics Unit and the Departments of Community Medicine and Clinical \\ Surgery, University of Edinburgh, and the General Surgical Unit, Western General Hospital, Edinburgh
}

SUMMARY In a trial of 360 patients with hernia or varicose veins, day care surgery provided an economic alternative to the provision of surgical aftercare either in the surgical wards of a district hospital or in a convalescent hospital. There was only slightly more work for general practitioners. Most of the additional work for the community services was carried out by district nurses, with an average contact time in the postoperative period of 325 minutes for day care patients, compared with 186 minutes and 204 minutes respectively for patients admitted for 48 hours to the surgical or convalescent wards. Day care produced estimated savings of $£ 30$ compared with the costs of a 48-hour stay in the surgical wards, and savings of $£ 22$ compared with a 48-hour stay in the convalescent wards.

The move towards a shorter hospital stay after certain forms of surgery has implications not only for patients, their relatives, and hospitals, but also for the community health services. In particular, general practitioners and district nursing sisters will play a larger part in aftercare. Previous studies have examined the safety and acceptability of such a change (Garraway et al., 1978; Ruckley et al., 1978). This paper examines the cost or saving to the health service of a day care scheme, and its effects on work load.

\section{Methods}

RECORDING WORK LOAD AFTER DISCHARGE FROM HOSPITAL

Whenever they were in contact with a patient during the first 21 days after operation, members of the health service completed a short form which included contact time and travelling time if applicable. These forms were collated to give information for each day for the first seven postoperative days, and then for days 8 to 10,11 to 14 , and 15 to 21 .

COSTING HOSPITAL CARE

In this study, attention is directed to the differences in costs and resources between the three methods of surgical aftercare under test. The cost of the stay in the day care unit is not relevant because all patients went through this stage. Costing was done by the method used at Aberdeen by Russell (1974), which identifies direct and indirect costs incurred by a patient. The direct costs are the supplies and materials given directly to a patient, plus the cost of ward care, laboratory tests, physiotherapy, and so on. The indirect costs are the ward overheads, such as heating, portering, and rates, which can be allocated to wards and departments in proportion to their size; and general overheads, which are the costs of areas and services used by patients independently of their location or medical condition, such as laundry and linen, administration, and maintenance of grounds.

Russell determined the cost of ward care in relation to four levels of nursing dependency within a range of 1 to 11 units of ward care. These definitions were particularly easy to apply in practice. To establish the 'direct' cost of ward care and the use of drugs, all wards in the study were monitored for two months. For every patient in every ward, the level of nursing dependency was noted in the evening by the ward sister, using Russell's definitions. In addition, all tests, drugs, infusions etc., ordered for patients in the trial, were recorded. The study nurse made spot checks on the recorded levels of nursing dependency and use of drugs, etc., and encountered no inconsistencies. The costs of drugs were ascertained from the pharmacy. The cost per unit of ward care was calculated by taking the total 
ward salary bill over the two-month study period, including national insurance contributions, etc., and dividing by the number of units of care delivered in this period. For medical staff, the fraction of their time spent on ward duties was used to multiply their salary accordingly.

For general overheads, the annual expenditure (Scottish Health Service Costs, 1976) was divided by the number of impatient days in 1975-76 to give a cost of general overheads per patient day. The ward overheads were calculated from the annual figures on a pro rata basis for the two-month study period. This was divided by the number of patient days spent in the ward to give a ward overhead cost per patient day. All costs reported are for 1975-76.

\section{Results}

\section{USE OF COMMUNITY HEALTH SERVICES}

GENERAL PRACTITIONers Figure 1 shows the mean amount of time (including travelling time) spent with patients in the trial by GPs in relation to the surgical aftercare provided. During the threeweek follow-up, the work load is significantly heavier with day care patients than with ward care patients, but the average difference is only eight minutes. The maximum amount of time spent with a patient was 88 minutes for ward care patients, 130 minutes for convalescent care patients, and 137 minutes for day care patients. At the other extreme, the percentages of patients who had no direct contact with their GPs in the follow-up period were $44 \%$, $41 \%$, and $42 \%$ respectively.

DISTRICT NURSES The pattern of visiting by district nurses is shown in Figure 2. For day care patients, the pattern was one of fairly intensive visiting in the early postoperative period as the defined routine demanded. Patients treated by ward care or convalescent care were visited by the district nursing sister only from the second postoperative day. From that point in time, the level of contact with district nursing sisters was similar in all groups. The average levels of district nursing sister contact time (including travelling) in the three-week follow-up period were 186 minutes, 204 minutes, and 325 minutes for ward patients, convalescent patients, and day care patients respectively. All patients were visited by a district nurse at some time, with a range of 20 to 980 minutes contact time.

OTHER PROFESSIONALS Only seven patients (one ward patient, three convalescent patients, and three home patients) had to be seen by other members of the medical and nursing professions, except when going back to hospital for the routine return visit or

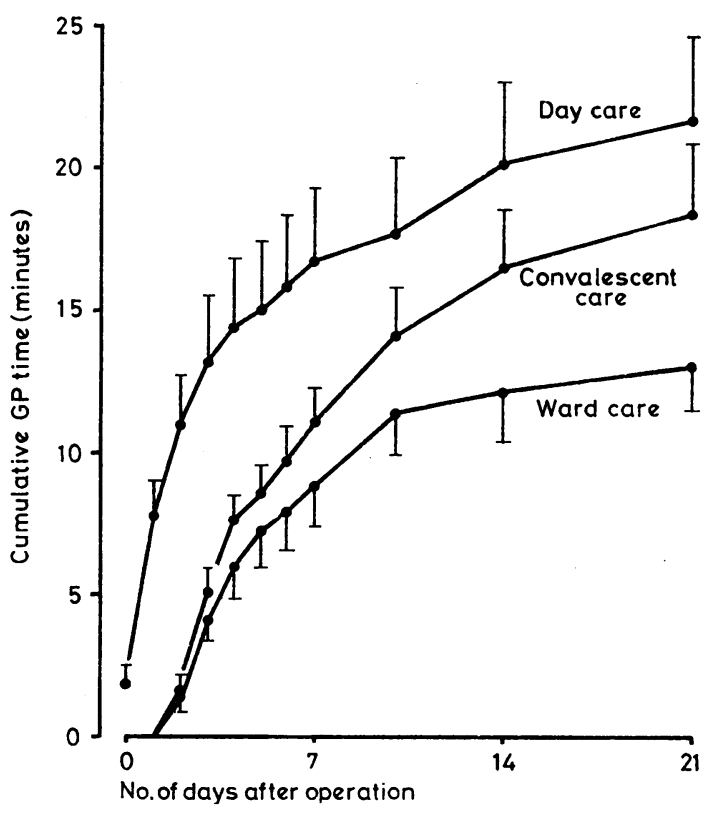

Fig. 1 Mean times (with standard errors) spent by general practitioners with patients in the three groups

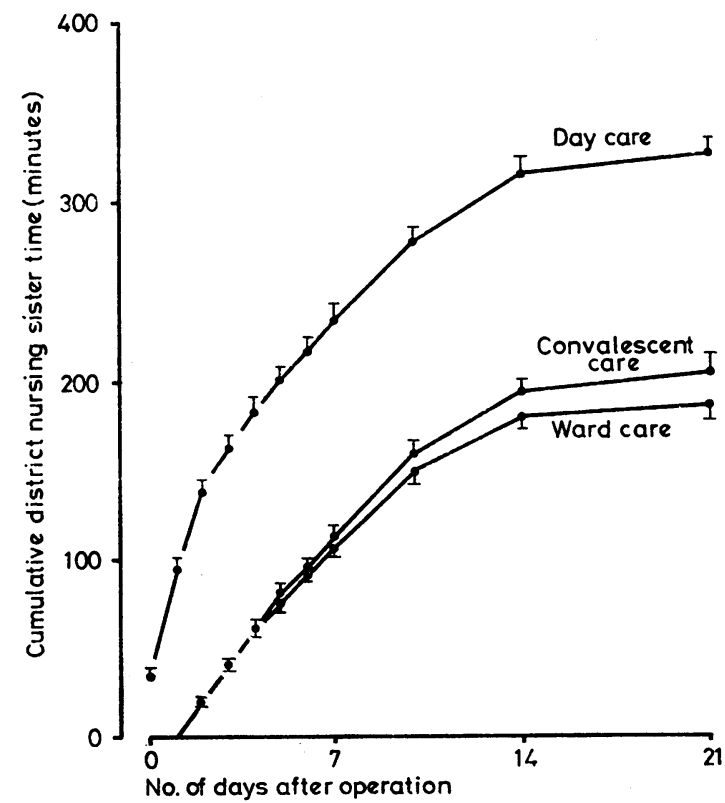

Fig. 2 Mean times (with standard errors) spent by district nursing sisters with patients in the three groups. 
readmission (Ruckley et al., 1978). Six were seen by a surgeon, either as an outpatient or at home, and one required a visit by a senior nursing officer. In a group of 360 patients this does not represent a serious work load.

USE OF HOSPITAL RESOURSES During the twomonth ward study, 23 patients from the trial were admitted to the wards. Twenty were placed at first in the nursing category corresponding to the nextto-lightest dependency, and on the following day they were placed in the lightest category, which accounts for three and one nursing units respectively, or four in all. The other three patients were all detained in hospital for a third day, two for medical reasons and one for a social reason.

The cost per unit of ward care, based on figures for the financial year $1975-6$, was $£ 2.53$ for the surgical wards and $£ 2 \cdot 25$ for the convalescent wards, giving a total cost of $£ 10.12$ and $£ 9.00$ respectively for the study patient whose recovery was straightforward. The indirect costs for a 48-hour admission (including catering) were calculated to be $£ 27.76$ and $£ 18.75$ respectively.

The use of other resources was minimal. The average cost of drugs for patients in the ward care group was $12 p$, with a maximum of $39 p$. In the convalescent wards, the mean cost was $3 p$ with a maximum of $9 \mathrm{p}$. There were no requests for any biochemical tests, $x$-rays, or any other item to which a cost might be attached. Total ward care costs were approximately $£ 38$, and convalescent care costs $£ 28$. For comparison, the Scottish Health Service Costs (1976) report an average of $£ 71$ for a two-day inpatient stay at the Western General Hospital and £38 at the Astley Ainslie Hospital.

The lightest burden was placed on community health services when patients were admitted to the surgical wards. Compared with ward care patients, convalescent care patients used, on average, an extra five minutes of GP time and 18 minutes of district nursing sister time. Day care took eight minutes more GP time and 139 minutes more district nursing sister time than ward care.

Costing district nursing sister time at average rates of pay, with some allowance for time spent on administration, the additional cost over that of ward care was of the order of $£ 1.00$ per patient for convalescent care, and $£ 6.00$ for day care. For day care, it is necessary to determine the suitability of the home circumstances. For this, a self-administered questionnaire and a home visit by the study nurse were used (cost: approximately $£ 1 \cdot 00$ ).

There was also the cost of ambulance travel from hospital. All patients discharged to the convalescent hospital or discharged home after surgery needed transport by ambulance. The finance division of the Scottish Ambulance Service quoted a cost of $16 p$ per mile as the average for 1975-6. This added approximately $£ 1.00$ to the average cost of convalescent care or home care. On discharge two days after operation, few patients used the ambulance service, and we considered these costs as negligible.

If the figures given above are combined with the hospital costs for a patient whose recovery is straightforward, the cost of a patient treated by ward care was $£ 46$, by convalescent care $£ 38$, and by day care £16. There was an overall saving to the health service of approximately $£ 30$ by using home discharge instead of the surgical wards (Table).

Table Comparative costs of three types of postoperative aftercare

\begin{tabular}{|c|c|c|c|}
\hline & Ward & Convalescent & Day care \\
\hline $\begin{array}{l}\text { Hospital costs after } \\
\text { discharge from day } \\
\text { unit } \dagger\end{array}$ & $\mathfrak{f 3 8}$ & $£ 28$ & - \\
\hline $\begin{array}{l}\text { District nursing } \\
\text { service* } \\
\text { Ambulance service } \\
\text { Nurses' home }\end{array}$ & $\underline{£ 8}$ & $\begin{array}{l}\text { } 9 \\
\text { f1 }\end{array}$ & $\begin{array}{r}£ 14 \\
f 1\end{array}$ \\
\hline $\begin{array}{l}\text { assessment visit } \\
\text { Total }\end{array}$ & $\overline{£ 46}$ & $£ \overline{38}$ & $\begin{array}{r}f 1 \\
f 16\end{array}$ \\
\hline
\end{tabular}

*These figures are based on a presumed cost at 1975-76 rates of $£ 2.50$

per hour (salary approximately $£ 1 \cdot 50$ per hour)
tExcluding the costs of dressings, drugs, surgery, and stay in the day unit

\section{Discussion}

The main reason for moving towards a policy of shorter hospital stays after surgery is to release expensive surgical beds. For patients undergoing surgery for varicose veins or inguinal hernia, Ruckley et al. (1978) found that discharge directly home after recovery in a day care area does not carry risks for those with adequate facilities who have a relative or friend able to provide postoperative care for the patient at home. Although we have shown that the savings to the health service are not as large as might be thought on the basis of average daily hospital costs, these savings are nevertheless substantial, bearing in mind the large number of patients who are likely to be able to benefit from this form of surgical aftercare.

The costing procedure utilised in this study gives a reasonable indication of the relative costs of the various methods of providing surgical aftercare. However, the full implications for the health service may be more complex. Clearly, if convalescent beds are not available, convalescent care cannot be considered. If there is an acute local shortage of district nursing sisters, home discharge is unlikely to be satisfactory unless an undue burden is placed on general practitioners. Again, if there is already an 
under-utilisation of surgical beds, reducing the number of patients still further will increase the unit cost of treating the remaining patients. If outpatient surgery were initiated in a situation where there was no existing provision for patients to recover after operation before home discharge, there would be an additional cost for day care not encountered in this study.

In the situation in which this trial was carried out, the main implications for the health service of day care versus ward care appear to be as follows. An increased work load is placed upon the district nursing service with a minimal increase in the use of GP time. In the hospital, surgical beds are made available for other patients who are more in need of specialised medical and nursing skills. Thus, there is not likely to be any immediate reduction in hospital expenditure because of the move towards early home discharge, but the turnover of patients will tend to increase, causing a reduction in the overall cost per patient, and a reduction in waiting lists.

This study has examined the economic consequences for the health service, but its ramifications are obviously wider. On the debit side of home care, the caring person may have to miss work. Approximately half of the caring relatives in the study needed some form of leave from work, and a holiday with pay was the most popular, with a mean number of 3.7 days' leave. Also, the cost to the patient of being at home will no doubt be greater than the cost of being cared for in hospital. On the credit side, if home discharge reduces the time spent on waiting lists it is reasonable to suppose that the total amount of time off work could be reduced substantially, producing an economic gain.

The savings reported in this study are the result of comparing day care with a two-day hospital stay. But the standard practice of many surgeons is to recommend a hospital stay longer than two days, so the potential saving in moving to day surgery is larger. Scottish hospital inpatient statistics for 1975 (1977) showed that the mean duration of hospital stay in Scotland for hernia repair was eight days and for varicose vein surgery six days. The saving in day care compared with a seven-day stay in a surgical unit would be approximately $£ 100$.

We are grateful to the many colleagues who helped with this trial. The study was supported by a grant from the Scottish Home and Health Department.

Reprints from R. J. Prescott, Medical Computing and Statistics Unit, Medical School, Teviot Place, Edinburgh EH8 9AG.

\section{References}

Garraway, W. M., Cuthbertson, C. J. C., Fenwick, N., Ruckley, C. V., and Prescott, R. J. (1978). Consumer acceptability of day care after operations for hernia or varicose veins. Journal of Epidemiology and Community Health, 32, 219-221.

Ruckley, C. V., Cuthbertson, C. J. C., Fenwick, N., Prescott, R. J., and Garraway, W. M. (1978). Day care after operations for hernia or varicose veins-a controlled trial. British Journal of Surgery, 65, 456-459.

Russell, E. M. (1974). Patient Costing Study. Scottish Health Services Studies No. 31, Scottish Home and Health Department: Edinburgh.

Scottish Health Service Costs 1976 (1976). Scottish Health Boards.

Scottish Hospital Inpatient Statistics, 1975 (1977). Information Services Division of the Common Services Agency. Scottish Health Service: Edinburgh. 